\title{
EXPERIMENTAL AND NUMERICAL INVESTIGATION OF TOWING RESISTANCE OF THE INNOVATIVE PNEUMATIC LIFE RAFT
}

\author{
Zbigniew Burciu ${ }^{1)}$ \\ Teresa Abramowicz-Gerigk ${ }^{1)}$ \\ Jacek Jachowski ${ }^{1)}$ \\ Edyta Kornacka ${ }^{1)}$ \\ Michał Wawrzusiszyn ${ }^{2)}$ \\ 1) Gdynia Maritime University, Poland \\ 2) Ship Design and Research Centre, Poland
}

\begin{abstract}
The paper presents the experimental and numerical investigations of a novel design of a pneumatic life raft in calm water conditions. Two main issues were considered: the life raft performance under tow and its resistance in calm water conditions. The experiment and CFD simulations were performed by using the full scale prototype to eliminate the scale effect. The towing tank tests confirmed the results of numerical computations. The compatibility of the results of numerical and experimental tests was high mainly because the new life raft does not deform under the hydrodynamic and aerodynamic loads. The characteristics similar to rigid body behaviour result mainly from a new construction and materials used for manufacturing the life raft.
\end{abstract}

Keywords: search and rescue, pneumatic life raft, towing resistance

\section{INTRODUCTION}

The main trends in design of ships and floating objects are design for safety and design for operation, based on the complex approach containing the predicted operational characteristics and functions of an object as an element of transport system. In the systemic approach to the ship safety assessment the reliability of life saving appliances on board ship is a vital element included in the ship design process [7].

Life saving appliances in the time of search and rescue (SAR) action are considered as the elements of SAR system and the determination of their performance is vital for the assessment of SAR action reliability $[2,4]$.

The pneumatic life raft is the most commonly used type of life saving appliances on board ships and recreational boats. Due to hydrostatic release mechanisms the pneumatic life raft can be used in most emergency cases, in sudden accidents of ship loss, being automatically launched from $4 \mathrm{~m}$ depth and inflated on the water surface.
The main idea of the design of a pneumatic life raft has not been changed since more than 50 years. The basic objectives are still the small storage space on the deck on board ship, operation independent on weather conditions, automatic launch when ship is sinking, low cost of purchase and operation.

The lack of any significant changes in the life raft construction, improving its operational parameters, is due to the economical reasons. Ship owners are interested in the purchase of not expensive equipment. The main criterion is to satisfy the requirements and availability of maintenance services. The requirements are comprised in the classification rules, European Union directives and international lifesaving appliances (LSA) code $[6,10,11,14]$.

The most important factors determining the success of SAR action are the survivor's time to survive, search probability and efficiency of search and rescue action.

The main conclusions coming from the reports of SAR actions at sea and the own research conducted in real sea 
conditions by Gdynia Maritime University $[4,5,6]$ show the direct influence of life raft shape, construction materials, equipment and operational characteristics on the above mentioned factors. One of the main operational characteristics of a life raft is its performance under tow.

The paper presents the CFD (Computational Fluid Dynamics) simulations of the life raft performance under tow, carried out at Gdynia Maritime University. The results of the numerical prediction of towing resistance were compared with the results of physical model tests. The tests were carried out in the towing tank of Ship Design and Research Centre in Gdansk according to the research program developed at Gdynia Maritime University.

The comparison of CFD computations and real- scale measurements of life raft towing characteristics has been done in two loading conditions, with a drogue? and without it.

\section{A PROTOTYPE OF INNOVATIVE PNEUMATIC LIFE RAFT}

Gdynia Maritime University having multi- year experience in testing life rafts in real sea conditions has developed procedures to determine the life raft operational safety characteristics.

On the basis of this experience a prototype of an innovative life raft has been manufactured by Lubawa S.A. in scientific cooperation with Gdynia Maritime University and Military Institute of Technical Engineering in Wroclaw ( very experienced in special materials design), within the frames of R\&D project $[13,18]$.

The novel construction included a pneumatic two-layer floor with a gravitational drainage system, two-layer canopy and entrance lock designed mainly for cold protection and resistance against deformation of the construction [17].

The life raft has been manufactured of the rubberized textile of a good resistance to heavy sea weather conditions, good resistance to UV radiation, low and high temperatures, ageing and high resilience to wear and rupture.

The bright orange colour and radar reflectors integrated with the canopy increase the life raft detectability in the ranges of visual observation, thermal infra-red and radar detection [20].

The new life raft consists of four independent inflated compartments: two ballast compartments, canopy compartment and pneumatic floor compartment. The properly inflated compartments suffer no deformations under towing and show much better characteristics similar to the rigid body behaviour in comparison to the old type life rafts, manufactured in Poland over 10 years ago by Stomil Grudziądz enterprise - Fig. 1.

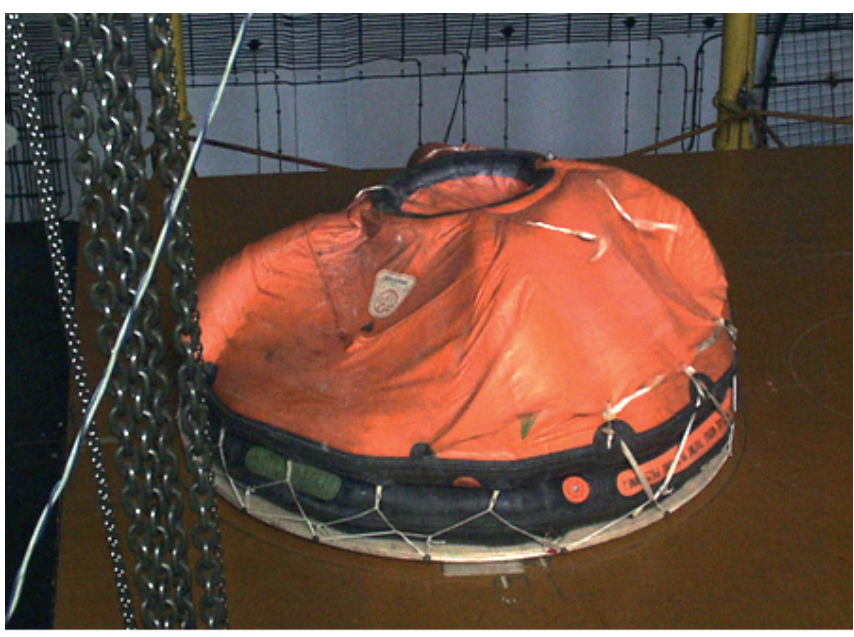

Fig. 1. Deformation of the canopy of a 6-person life raft - real scale tests in the wind tunnel of Institute of Aviation, Warsaw, Poland [4]

The new designs of life saving appliances having characteristics not covered by the requirements of SOLAS (Safety of Life at Sea) Convention Part III and LSA Code should be recognized by Maritime Administration and meet the requirement of equal or higher safety level than that adopted in the rules. Before the recognition Maritime Administration should confirm that according to IMO requirements the new lifesaving appliances have been tested and comply with the requirements of SOLAS Convention and LSA Code [11].

In the light of the regulations a fully occupied life raft with operating drogue should withstand towing with the speed of at least 3 knots in calm water conditions. The total mass of a life raft with equipment and container should be no greater than $185 \mathrm{~kg}$. The canopy should not collect the water and the towline breaking force should be not less than $7 \mathrm{kN}$ for the life rafts of capacity no greater than 9 persons.

The recommended standard mass of a survivor to be assumed in the calculations should be equal to $75 \mathrm{~kg}$. This is much less than the average mass of a seaman [15], therefore the mass taken in the experiments and calculations presented in this paper was equal to $82.5 \mathrm{~kg}$ according to Det Norske Veritas (DNV) classification rules [17].

This assumption allows to certify the life raft by DNV-GL (Det Norske Veritas -Germanisher Lloyd), because all vessels which keel was laid up over 1 January 2012, with respect to the DNV rules [17], should be equipped with life rafts, approved for the assumed mass of $82.5 \mathrm{~kg}$. This mass should be also taken in calculations of devices for picking up survivors from the water [9].

The design calculations for the life raft concerned hydrostatic, hydrodynamic and aerodynamic characteristics, and characteristics influencing the probability of life raft detection (Fig. 2).

For the assumed mass of a survivor equal to $82,5 \mathrm{~kg}$ the total mass of the life raft including 8 persons and equipment was $760 \mathrm{~kg}$.

The elements of the life raft, their masses and areas used in calculations are presented in Fig. $3[3,18]$. 


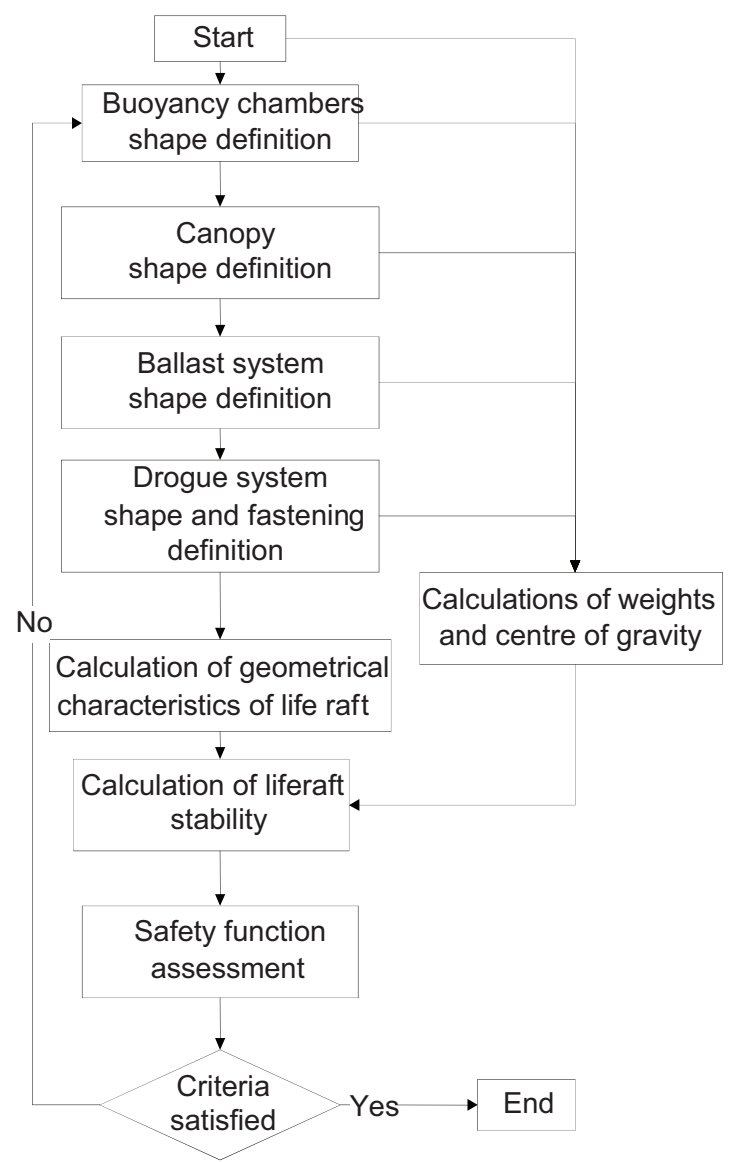

Fig. 2. Life raft design characteristics influencing probability of detection [1]

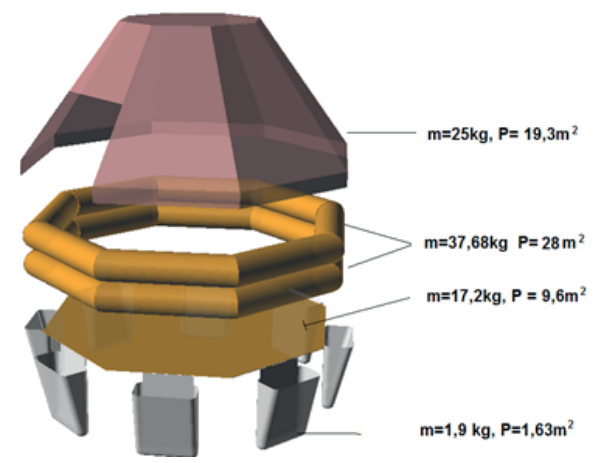

Fig. 3. The elements of the life raft, masses $(m)$ and areas $(P)$ [18]

The weights of survivors were modelled by ballast. For that purpose the plastic containers were positioned on the floor of the life raft. For the loading condition equivalent to weight of 1 person and equipment - the ballast was installed at the side of the towline connection. In second loading condition equivalent to the weight of 8 persons and equipment the ballast was distributed evenly along the sides of the life raft.

Due to a specific character of the tested object, the tests were carried out according to a non- standard test procedure. The life raft was towed by the carriage; the towline was installed at the floor level and was connected to the dynamometer at the carriage (Fig. 4).

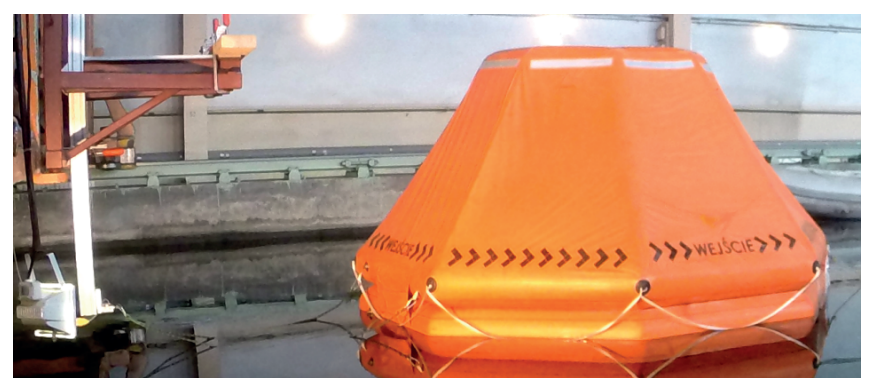

Fig. 4. Model test of the novel life raft tied to the carriage, loading condition: 1 person, $V=0 \mathrm{~m} / \mathrm{s}$

The measuring range of dynamometer was $1500 \mathrm{~N}$ and measurement uncertainty at the $95 \%$ confidence level was $0.075 \mathrm{~N}$.

For the ballast corresponding to 8 persons and towing speed of $0.7 \mathrm{~m} / \mathrm{s}$ and $1.5 \mathrm{~m} / \mathrm{s}$ the life raft was equipped with a drogue.

The mean values of the measured resistance are presented in Tab. 1.

Tab. 1. Mean resistance values of the life raft

\begin{tabular}{|c|c|c|c|c|}
\hline \multirow{2}{*}{ 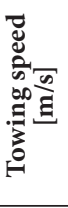 } & \multirow[b]{2}{*}{ 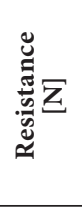 } & \multicolumn{3}{|c|}{ Loading condition } \\
\hline & & 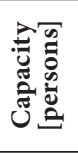 & 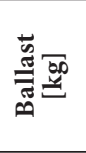 & 总泀 \\
\hline 0,70 & 176,3 & 1 & 82,5 & No \\
\hline 1,50 & 908,1 & 1 & 82,5 & No \\
\hline 0,70 & 202,8 & 8 & 660,0 & No \\
\hline 0,70 & 295,8 & 8 & 660,0 & Yes \\
\hline 1,50 & 952,9 & 8 & 660,0 & Yes \\
\hline 1,50 & 1419,9 & 8 & 660,0 & Yes \\
\hline
\end{tabular}

During the test of the life raft with $660 \mathrm{~kg}$ ballast and connected drogue at speed $1.5 \mathrm{~m} / \mathrm{s}$ the measured resistance has exceeded measuring range of the dynamometer. As a result it caused a decrease of mean resistance value for this configuration.

The test results of the trials are presented in Fig. 5.

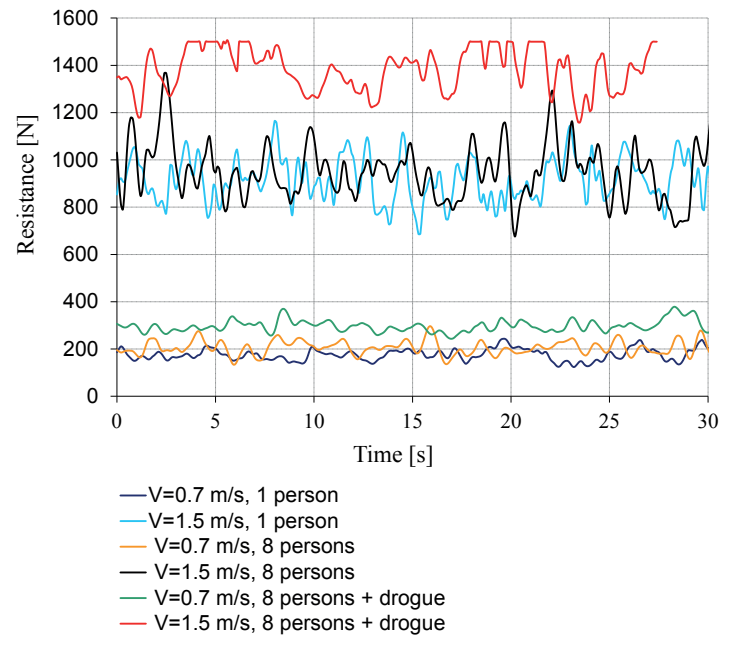

Fig. 5. Towing resistance in time series - model tests results of the life raft 


\section{NUMERICAL PREDICTION OF LIFE RAFT TOWING RESISTANCE}

The CFD technique allows the modelling of a space surrounding the life raft divided into cells. The applied Reynolds-averaged Navier-Stokes (RANS) equations give the approximate time-averaged solutions in each cell. The CFD software utilized in the presented research was Flow Vision HPC, whose code is based on the finite volume method (FVM) and uses the VOF method for the free surface problems solutions [19].

The simulations were performed by using the overlapping mesh technique. The assumption of this approach is that one of the meshes is stationary in the whole computational domain, related to the global reference system (GPS). The second mesh modelling the life raft is related to a local reference system (LRS), whose movement is determined by model of six degrees of freedom (6DOF) implemented into the program, with special consideration of three degrees of freedom (3D) - pitch, roll and heave.

The numerical 3D model of the life raft used in CFD towing simulations and computational domain shape with the given boundary conditions are presented in Fig. 6 and 7.

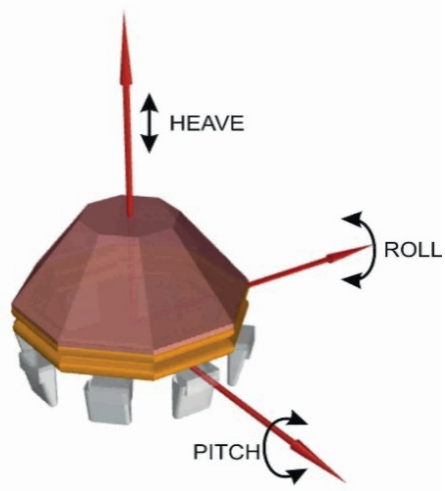

Fig. 6. Numerical model of the life raft and reference system related to the life raft

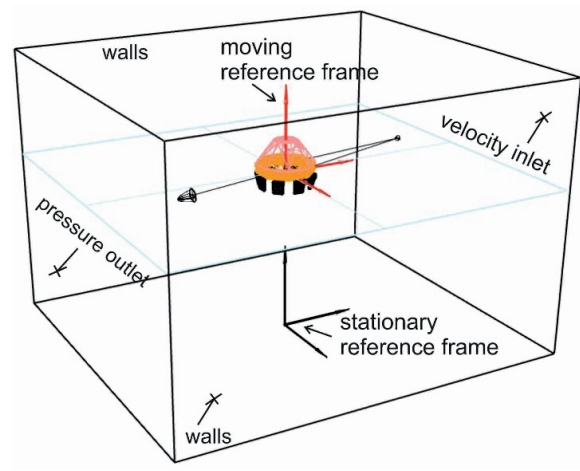

Fig. 7. Computational domain and arrangement of the reference systems and boundary conditions

The high accuracy of computation is achieved by solving the governing equations in the 'free surface' cells (the cells partly filled with liquid). The simulations of turbulent flows were based on the eddy viscosity concept and $k-\varepsilon$ semi-empirical turbulence model was applied. The practical application of the Flow Vision software is based on the consecutive steps performance. They are related to the geometry identification, modelling, pre-processing, solving the equations and postprocessing (Fig. 8).

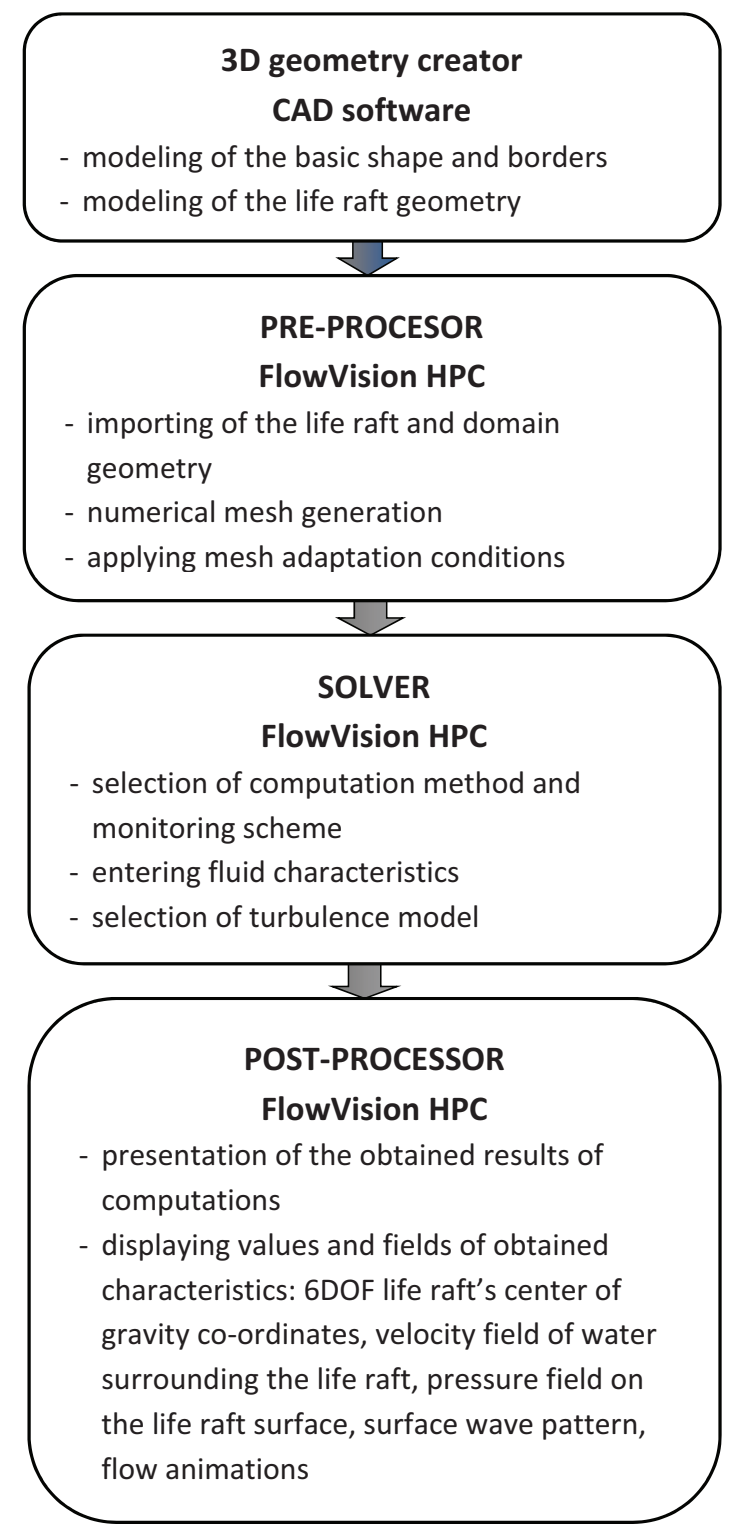

Fig. 8. Schematic diagram of Flow Vision HPC software application

The assumptions accepted in the CFD modelling of the life raft towing are as follows:

- 3-dimensional flow simulations are used,

- simulations are performed in full scale,

- calculations are based on the reverse flow method,

- simulations are performed by using overlapping meshes enabling life raft pitch and roll motions,

- the semi-empirical $k$ - $\varepsilon$ turbulence model was applied,

- the VOF method was applied for the free surface problems, 
- the life raft in simulations was treated as a rigid body with the flat bottom, without deformations related to the loading,

- the water pockets situated under the life raft bottom, providing ballast to ensure the life raft stability were modelled as non-deformable volumes,

- the divergent time step in simulations is dependent on convergence of solution.

The simulations were carried out in the domain of discretized structural mesh consisted of 1.6 million cells. The structural mesh is presented in Fig. 9.
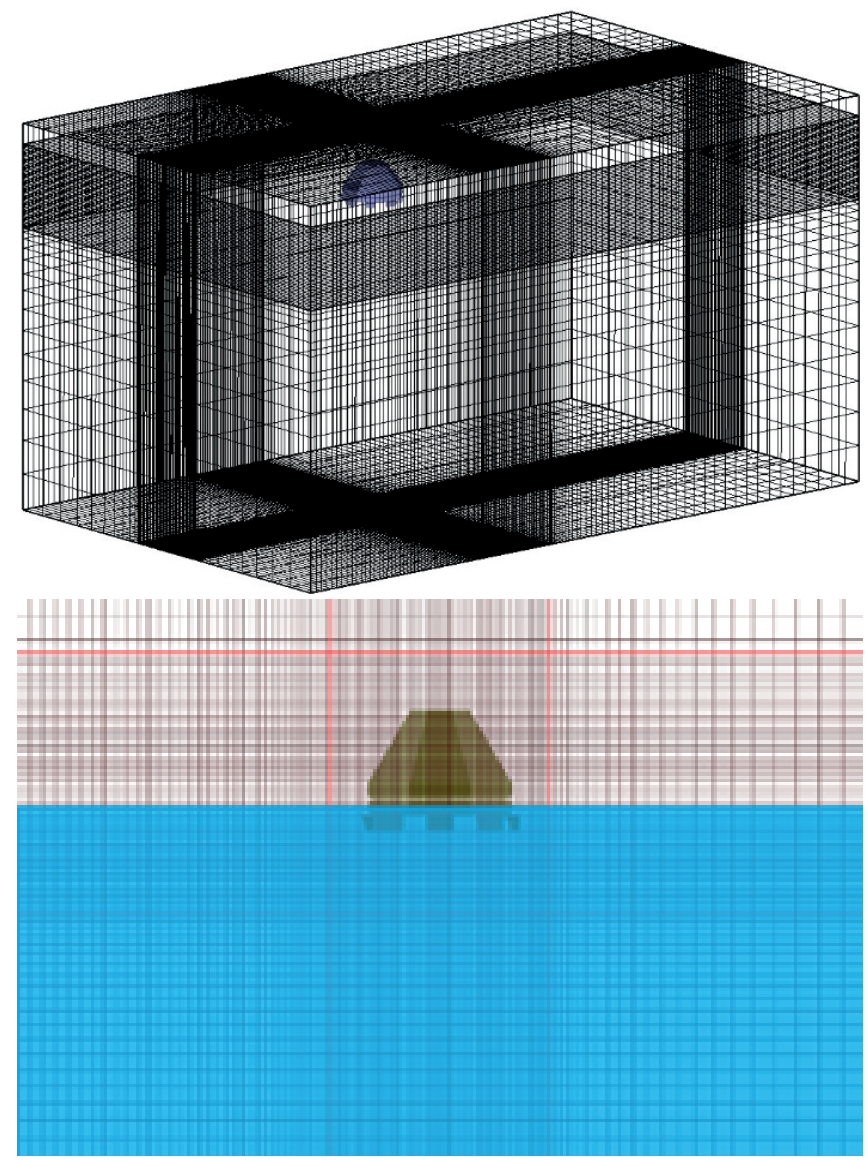

Fig. 9. Domain of the flow with hexahedral mesh

The simulations were carried out in the assumed domain in calm water conditions. The test speeds of the life raft were equal to the speeds assumed during the model tests, i.e. 0.7 $\mathrm{m} / \mathrm{s}$ and $1.5 \mathrm{~m} / \mathrm{s}$. The initial conditions were defined as follows: $2 \%$ turbulence intensity level, length of mixing equal to 0.07 of the life raft diameter, Reynolds numbers for the assumed kinematic viscosity coefficient of $10^{-6} \mathrm{~m}^{2} / \mathrm{s}$ were equal to: $\mathrm{Re}=1,855 \mathrm{E} 6$ for the towing speed of $0,7 \mathrm{~m} / \mathrm{s}$ and $\mathrm{Re}=3,975$ E6 for the towing speed of $1.5 \mathrm{~m} / \mathrm{s}$.

The loading condition was equivalent to 8 persons and equipment on board. The simulations were carried out both with and without the drogue

The drogue resistance was computed by using CFD simulation, with the same settings of the solver as the settings used for the life raft. The drogue was modelled as a thin-walled rigid body, placed in the flow near the free surface.

The points of the life raft towline fastening and drogue line fastening were assumed in the centre of gravity (COG). With this assumption the line of action of towing force and line of action of drogue resistance force intersect COG hence life raft pitching moment can be neglected in calculations. The towline and sea anchor configuration adopted in CFD simulation is presented in Fig. 10.

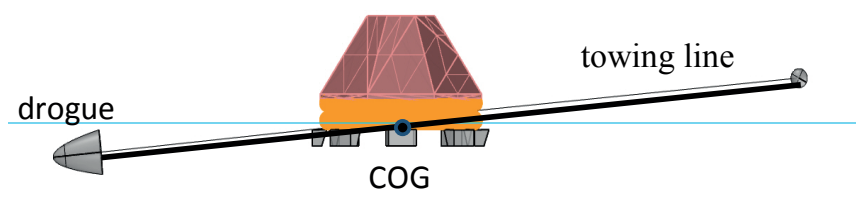

Fig. 10. Towline and drogue configuration

\section{RESULTS OF COMPUTATIONS}

The hydrodynamic resistance of the life raft and drogue were calculated separately in calm water conditions. The total towing resistance was a sum of life raft and drogue resistance forces. The final result of the simulation obtained after the post-processing comprises the general flow pattern as well as the velocity and pressure fields which are important elements of the conducted study.

The positions of the life raft on the free surface in steady states at two towing speeds are presented in Fig. 11 and 12.

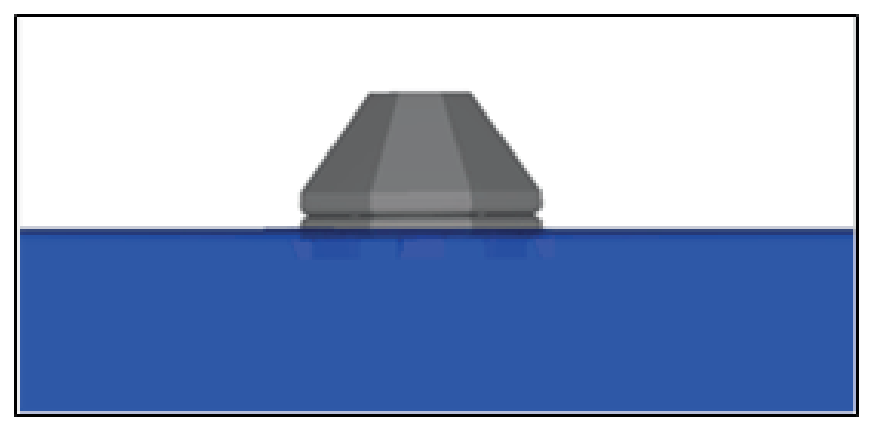

Fig. 11. CFD simulation results - free surface deformation for $0.7 \mathrm{~m} / \mathrm{s}$ towing velocity

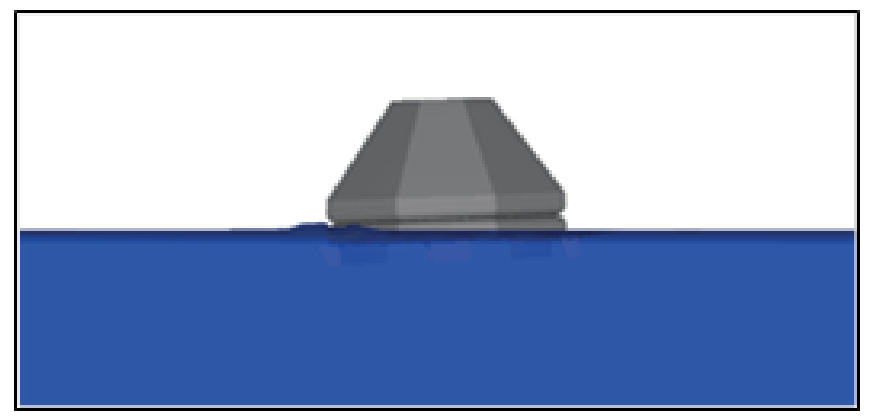

Fig. 12. CFD simulation results - free surface deformation for $1.5 \mathrm{~m} / \mathrm{s}$ towing velocity 
The towing resistance function in time series obtained from CFD simulation compared with the results of model tests at speeds $0.7 \mathrm{~m} / \mathrm{s}$ and $1.5 \mathrm{~m} / \mathrm{s}$ are presented in Fig. 13 .
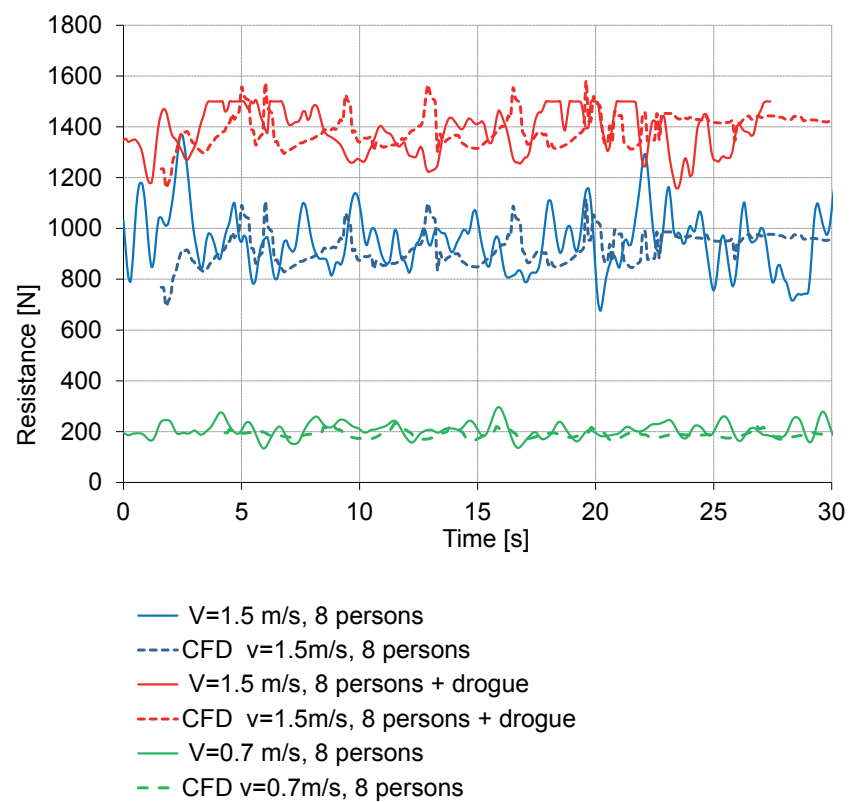

Fig. 13. Model tests results of the life raft towing compared to CFD simulation for two towing velocities: $0.7 \mathrm{~m} / \mathrm{s}$ and $1.5 \mathrm{~m} / \mathrm{s}$.

The variability of the life raft resistance in time domain is determined by the unsteady simulation mode of the object in three degrees of freedom (Fig. 6). The resistance fluctuations are also determined by the temporary changes of the life raft position relative to the flow direction.

The percentage share of the mean drogue resistance at 1.5 $\mathrm{m} / \mathrm{s}$ speed is $51 \%$ (Tab. 2).

Tab. 2. Mean resistance values of the drogue

\begin{tabular}{|c|c|c|}
\hline \multicolumn{2}{|c|}{ Resistance [N] } & $\begin{array}{c}\text { Drogue resistance / Life raft } \\
\text { resistance [\%] }\end{array}$ \\
\cline { 1 - 2 } Life raft & Drogue & 51 \\
\hline 921 & 466 & \\
\hline
\end{tabular}

The wave system generated by the life raft under tow at $1 \mathrm{~m} / \mathrm{s}$ and $1,5 \mathrm{~m} / \mathrm{s}$ and flow velocity distribution on the free surface are presented in Fig. 14.

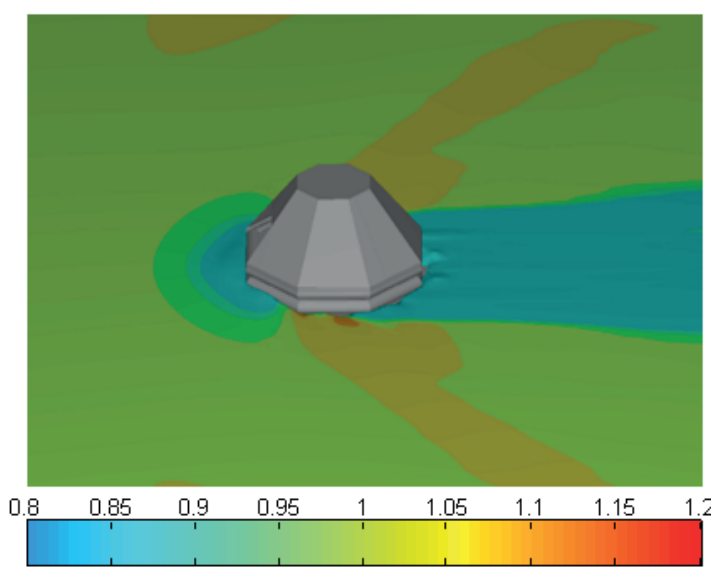

$\mathrm{m} / \mathrm{s}$

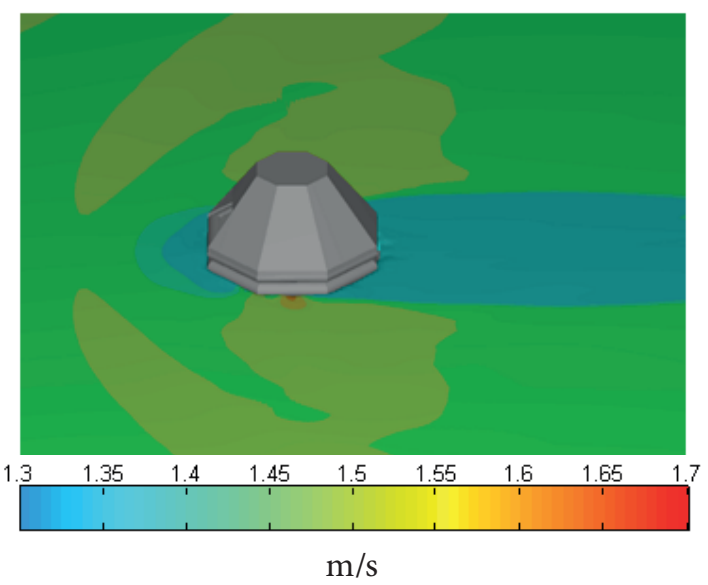

Fig. 14. Wave system generated by the life raft under tow at $1 \mathrm{~m} / \mathrm{s}$ and $1,5 \mathrm{~m} / \mathrm{s}$, flow velocity distribution on the free surface.

Tab. 3. Mean resistance values obtained from physical model tests and CFD simulation

\begin{tabular}{|c|c|c|c|c|}
\hline \multirow{2}{*}{$\begin{array}{c}\text { Speed } \\
{[\mathbf{m} / \mathbf{s}]}\end{array}$} & \multirow{2}{*}{$\begin{array}{c}\text { Drogue } \\
\text { application }\end{array}$} & CFD & Model tests & $\begin{array}{c}\text { Mean Resistance [N] } \\
\text { percentage } \\
\text { error } \\
{[\%]}\end{array}$ \\
\hline 0.7 & No & 189 & 205 & $7.9 \%$ \\
\hline 1.5 & No & 921 & 957 & $3.7 \%$ \\
\hline 1.5 & Yes & 1388 & 1383 & $-0.3 \%$ \\
\hline
\end{tabular}

The compatibility of the results of numerical calculations and experimental tests was high (Tab. 3) mainly because the new life raft does not deform under hydrodynamic and aerodynamic loads.

The characteristics similar to the rigid body behaviour mainly result from a new construction and material of the life raft, especially the life raft canopy [12].

The ballast chambers (water pockets) were modelled in CFD simulations as rigid bodies with front face areas equal to the areas of water inlet into a pocket (Fig. 15).

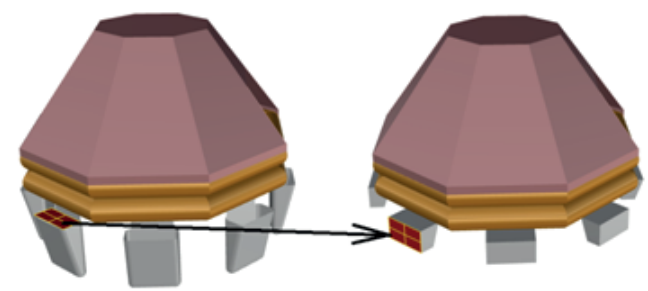

Fig. 15. Model of water pockets used in CFD simulation

The observed deformations of the water chambers during physical model tests were small and there was no significant influence of their deformation on the calculated resistance. 


\section{CONCLUSIONS}

There were two main issues considered during verification of CFD modelling of the flow around the pneumatic life raft: prediction of its towing resistance and performance under tow.

The experiment in towing tank and CFD calculations were performed by using the full-scale prototype to eliminate the scale effect.

The life raft during the towing tests was stable both with and without drogue.

In the loading condition corresponding to 8 persons on board, after application of the drogue the $32 \%$ increase of towing resistance was observed at speed $1.5 \mathrm{~m} / \mathrm{s}$.

The experiment and calculations were performed in calm water conditions. The earlier studies on towing performance of life rafts in waves show the significant influence of the length and elasticity of the drogue rope on the dynamical loads $[4,8,12,16]$. At small velocities the drogue rope is not strained and drogue gives small resistance, resulting in increase of yawing and decrease of stability. Further research will be aimed at the life raft performance in different loading conditions in wind and waves, what is of primary importance for the life raft operational reliability and safety analysis of survivors, development of the operational procedures and information for the rescuers.

\section{BIBLIOGRAPHY}

1. Abramowicz-Gerigk T., Burciu Z.: Inflatable life raft design for operation - novel solutions. $20^{\text {th }}$ International Conference on Hydrodynamics in Ship Design and Operation HYDRONAV'2014, Wroclaw, Poland, June 2014.

2. Abramowicz-Gerigk T., Burciu Z.: Safety assessment of maritime transport - Bayesian risk-based approach in different fields of maritime transport. Proceedings of IMAM 2013, $15^{\text {th }}$ International Congress of the International Maritime Association of the Mediterranean (IMAM), Spain, Developments in Maritime Transportation and Exploitation of Sea Resources. Guedes Soares \& Lopez Pena (eds), Volume 2, 2014 Taylor\&Francis Group, London, UK, pp. 699-703, 2013 ?.

3. Abramowicz-Gerigk T., Burciu Z., Kornacka E., Jachowski J., Stefurak W.: Innovative Liferaft. TransNav - The International Journal on Marine Navigation and Safety of Sea Transportation ,2015. Vol 9/4, pp. 573-577.

4. Burciu Z.: Modelling of search areas in the aspect of transport of persons at sea ( in Polish) Oficyna Wydawnicza Politechniki Warszawskiej ( Publishing House of Warsaw University of Technology), 2003.
5. Burciu Z., Grabski Fr.: The experimental and theoretical study on the reliability of the life rafts. Reliability Engineering and System Safety 96 (2011), pp. 1456-146.

6. EU Directive of Marine Equipment 96/98/EC. 1996.

7. Gerigk M.:Assessment of safety of ships after the collision and during the ship salvage using the matrix type risk model and uncertainties. In: Sustainable Maritime Transportation and Exploitation of Sea Resources. Proceedings of the $14^{\text {th }}$ International Congress of the International Maritime Association of the Mediterranean (IMAM), Volume 2, pp.715-719, Balkema, London , 2012.

8. Hervey C. L., Jordan D. J.: Model tests of inflatable life rafts in breaking waves. Final Report for U.S. Coast Guard. U.S. Department of Transportation, United States Coast Guard, Office of Engineering, Logistics, and Development, Washington, 1990.

9. IMO MSC.1/Circ.1447.: Guidelines for the Development of Plans and Procedures for Recovery of Persons From the Water. 2012.

10. IMO Resolution MSC. 48(66). Life Saving Appliances Code. 1996.

11. Code LSA - Life Saving Appliances, Including LSA code. 2010.

12. Marchenko A. V. J.: The floating behaviour of a small body acted upon by a surface wave. J. Appl Maths Mechs, 1999, Vol. 63, No. 3, pp. 471-478.

13. Patent application No. P.418573, Life raft, Polish Patent Office, 2016.

14. SOLAS'74.. International Convention of Safety of Life at Sea. International Maritime Organization, 1980

15. Standards for Life Rafts and Inflatable Rescue Platforms. Marine Safety Directorate Transport, Canada, Ottawa. 1992.

16. Raman-Nair W., Power J., Simoes Re A.: Towing dynamics of a life raft and fast rescue craft in a surface wave. Ocean Engineering, 35 ,2008, pp.1252- 1258.

17. Det Norske Veritas: Rules for Classification of Ships, Newbuildings, Hull and Equipment, Main Class, Part 3, Chapter 6: Life Saving Appliances and Arrangements. January 1998.

18. Gdynia Maritime University ( Navigational Faculty, Department of Ship Operation): Innovative means of transport for search and rescue at sea. Technical report 2014, R\&D Project No. POiG 01.04.00.00-272/13. 
19. https://fv-tech.com Flow Vision HPC, access date: 27-01-2016.

20. www. lubawa.com.pl.

\title{
CONTACT WITH THE AUTHORS
}

\author{
Zbigniew Burciu \\ e-mail: zbj@am.gdynia.pl \\ Gdynia Maritime University \\ Morska 81-87, 81-225 Gdynia \\ Poland
}

Teresa Abramowicz-Gerigk

e-mail:tagerigk@am.gdynia.pl

Gdynia Maritime University

Morska 81-87, 81-225 Gdynia

Poland

Jacek Jachowski

e-mail:jjaca@o2.pl

Gdynia Maritime University

Morska 81-87, 81-225 Gdynia

Poland

\section{Edyta Kornacka}

e-mail:e.kornacka@wn.am.gdynia.pl

Gdynia Maritime University

Morska 81-87, 81-225 Gdynia

Poland

\section{Michał Wawrzusiszyn}

e-mail: michal.wawrzusiszyn@cto.gda.pl

Ship Design and Research Centre

Szczecińska 65, 80-392 Gdańsk

Poland 